\title{
STRUKTUR DAN KOMPOSISI VEGETASI RIPARIAN PADA HABITAT IKAN PELANGI ARFAK (Melanotaenia arfakensis, Allen 1990) DI SUNGAI NIMBAI DAN AIMASI PRAFI MANOKWARI
}

\section{(Structure and Composition of Riparian Vegetation as A Habitat for Rainbow Fish [Melanotaenia arfakensis, Allen 1990] Alongside Nimbai and Aimasi Rivers of Prafi, Manokwari)}

\author{
Duma Tato Sanda ${ }^{1}$ Hans FZ. Peday ${ }^{1 凶}$ dan Alexander Rumatora ${ }^{1}$ \\ Jurusan Kehutanan, Fakultas Kehutanan Universitas Papua Manokwari, Papua Barat, \\ 98314. Tlp/Fax: +62986211065. \\ ${ }^{\square}$ Penulis Korespondensi: Email: hanspeday@gmail.com \\ Diterima: 12 Oct 2019| Disetujui: 08 Nov 2019
}

\begin{abstract}
Abstrak
Penelitian ini bertujuan untuk mengetahui tipe vegetasi riparian, struktur dan komposisinya sebagai habitat ikan pelangi arfak di sekitar sungai Nimbai and Aimasi daerah Prafi Manokwari. Data vegetasi diambil pada 8 lokasi dengan metode pengambilan data melalui desain plot sebanyak 5 di sepanjang sisi sungai Nimbai dan 3 sepanjang sisi sungai Aimasi melalui pengamatan tegakan semai, pancang, tiang dan pohon. Pada tingkatan semai dibuat plot dengan ukuran $4 \mathrm{~m}^{2}$, pancang dengan plot ukuran $25 \mathrm{~m}^{2}$, pancang dengan plot ukuran $100 \mathrm{~m}^{2}$, serta tingkat pohon dengan plot ukuran $400 \mathrm{~m}^{2}$. Hasil penelitian menunjukkan bahwa pada sungai Nimbai, terdapat sebaran vegetasi riparian di sisi sungai, terutama pada bangian tengah dan hulu yang mana masih dalam kondisi baik, sementara pada bagian hilir cenderung mulai mengalami perubahan yang disebabkan oleh kegiatan kelapa sawit, pertanian dan pembukaan lahan, serta pemukiman. Sebaliknya, kondisi vegetasi riparian terlihat dalam kondisi baik pada sisi sungai Aimasi. Tutupan vegetasi jenis riparian disekitar sungai Nimbai didominasi oleh tipe hutan sekunder tua, semak dan jenis rumputrumputan. Sementara tutupan vegetasi pada sungai Aimasi dominan adalah hutan primer dan sebagian berupa hutan sekunder muda. Selanjutnya perlu adanya upaya revegetasi disekitar hutan Nimbai terutama pada daerah hilir.
\end{abstract}

Kata kunci: vegetasi, riparian, endemik, Melanotaenia arfakensis, sisi sungai

\begin{abstract}
This study aims to determine the riparian vegetation types, its composition and structures as a habitat for rainbow arfak fish (Melanotaenia arfakensis) which is endemic on Nimbai and Aimasi river of Prafi in Manokwari. Data on riparian vegetation were taken at 5 locations along the riverbank of Nimbai river and 3 locations alongside to Aimasi river. Riparian vegetation that observed was on the left and right sides of the river, starting at seedling, sapling, pole, and tree stages. At the seedling stage, vegetation was then observed using sample plots of $4 \mathrm{~m}^{2}$, stage of $25 \mathrm{~m}^{2}$, stage of poles $100 \mathrm{~m}^{2}$ and tree stage $400 \mathrm{~m}^{2}$. The results showed that the existence of riparian vegetation alongside Nimbai river, especially in the central to upstream, is still quite natural, while the central part downstream tended to change, which was influenced by the activities of oil palm plantations, community
\end{abstract}


farming, pasture fields and settlement construction. Moreover, for Aimasi river, vegetation cover was still in a good shape. The vegetation cover of riparian forests around Nimbai river was influenced by the old secondary forest cover, bushes and grasslands. In the flip side, the vegetation cover types of Aimasi river were primary forest and young secondary forest cover. Efforts was needed to revegetate around Nimbai river area from the middle to the downstream.

Key words: vegetation, riparian, endemic, Melanotaenia arfakensis, riverside

\section{PENDAHULUAN}

Indonesia merupakan negara hutan tropis terluas ketiga di dunia setelah Brazil dan Republik Demokratik Kongo yang menyimpan keanekaragaman hayati sangat tinggi (mega biodiversity) (Lekitoo et al. 2017). Walaupun begitu, keanekaragaman hayati Indonesia terus berkurang akibat menyusutnya hutan secara terus menerus.

Ikan pelangi arfak (Melanotaenia arfakensis) merupakan salah satu keaneragaman hayati fauna di perairan Manokwari bahkan berstatus endemik. Ikan pelangi arfak ditemukan di perairan tawar sungai Nimbai dan sungai Aimasi (Manangkalangi dkk. 2009 dan 2010). Ikan tersebut juga dilaporkan berada di sungai Api, sungai Asiti dan sungai Atai di dataran tinggi Kebar (Manangkalangi 2009). Selain berpotensi sebagai biokontrol larva nyamuk (Manangkalangi dkk. 2009), ikan pelangi arfak juga berpotensi sebagai ikan hias karena warna tubuhnya yang cemerlang dan ukurannya yang relatif kecil. Ikan pelangi arfak telah dimasukkan dalam kategori rentan (vulnerable) dengan kriteria A2ce (IUCN 2012). Ikan pelangi arfak hanya ditemukan secara terbatas pada beberapa sungai di Manokwari, diduga berkaitan dengan perubahan habitat alaminya akibat aktivitas penebangan hutan skala besar untuk perkebunan kelapa sawit serta permukiman transmigrasi (Allen 1995 dalam Manangkalangi 2009) dan
(Polhemus dkk. 2004 dalam Manangkalangi dkk. 2012). Saat ini, populasi ikan pelangi arfak banyak mengalami gangguan, sehingga perlu dilakukan penelitian untuk mengetahui kondisi habitatnya terutama yang berkaitan dengan keberadaan hutan riparian.

Sungai Nimbai yang merupakan bagian dari sistem sungai Prafi di Distrik Prafi, merupakan salah satu sungai yang diketahui merupakan habitat ikan pelangi arfak. Penyebaran ikan pelangi arfak (Melanotaenia arfakensis) di daerah tersebut menurut Manangkalangi dkk. (2014) terbatas dan populasinya mengalami penurunan. Secara umum sungai Nimbai yang mengalir sepanjang tahun tersebut ditumbuhi oleh vegetasi tipe pengunungan hingga dataran rendah. Daerah tersebut juga telah mengalami cukup banyak perubahan fungsi hutan sementara kondisi sosial ekonomi masyarakatnya cukup beragam, seperti berprofesi sebagai petani sawit, buruh pabrik dan petani padi. Penelitian ini bertujuan untuk mengetahui tipe vegetasi riparian pada habitat ikan pelangi arfak di sungai Nimbai dan Aimasi.

\section{METODE PENELITIAN}

Penelitian ini dilakukan pada areal hutan riparian di sepanjang sungai Nimbai dan sungai Aimasi Distrik Prafi Manokwari yang pelaksananaanya dilakukan selama \pm satu bulan yakni dari 
Maret s/d April 2018. Obyek dalam penelitian ini adalah vegetasi riparian tingkat semai, pancang, tiang dan pohon di sepanjang sungai Nimbai dan Aimasi
Distrik Prafi Manokwari. Metode yang digunakan dalam penelitian ini adalah metode deskriptif dengan teknik sampling dan observasi (pengamatan) lapangan.

Tabel 1. Posisi geografis, ketinggian, lokasi penelitian, tipe hutan dan klasifikasi lokasi penelitian

\begin{tabular}{|c|c|c|c|c|}
\hline Koordinat & $\begin{array}{l}\text { Ketinggian } \\
(\mathrm{m} \mathrm{dpl})\end{array}$ & Lokasi & $\begin{array}{l}\text { Tipe hutan } \\
\text { riparian }\end{array}$ & Keterangan \\
\hline $\begin{array}{l}00^{\circ} 56^{\prime} 14^{\prime \prime} \mathrm{LS} \\
133^{\circ} 51^{\prime} 47,2 \text { " BT }\end{array}$ & 195 & $\begin{array}{l}\text { Sungai } \\
\text { Nimbai }\end{array}$ & Sekunder tua & $\begin{array}{l}\text { Relatif masih alami dan jauh dari } \\
\text { pemukiman }\end{array}$ \\
\hline $\begin{array}{l}00^{\circ} 56^{\prime} 3,4^{\prime \prime} \mathrm{LS} \\
133^{\circ} 51^{\prime} 47,9^{\prime \prime} \mathrm{BT}\end{array}$ & 188 & $\begin{array}{l}\text { Sungai } \\
\text { Nimbai }\end{array}$ & Sekunder tua & $\begin{array}{l}\text { Relatif masih alami walaupun } \\
\text { dekat dengan pemukiman }\end{array}$ \\
\hline $\begin{array}{l}00^{\circ} 55^{\prime} 30,6^{\prime \prime} \mathrm{LS} \\
133^{\circ} 51^{\prime} 22,8^{\prime \prime} \mathrm{BT}\end{array}$ & 169 & $\begin{array}{l}\text { Sungai } \\
\text { Nimbai }\end{array}$ & $\begin{array}{l}\text { Padang } \\
\text { rumput }\end{array}$ & $\begin{array}{l}\text { Dekat dengan areal perkebunan } \\
\text { kelapa sawit dan saluran } \\
\text { pembuangan limbah (IPAL) PT. } \\
\text { Perkebunan Nusantara II Prafi }\end{array}$ \\
\hline $\begin{array}{l}00^{\circ} 54^{\prime} 5,3^{\prime \prime} \mathrm{LS} \\
133^{\circ} 50^{\prime} 55,2^{\prime \prime} \mathrm{BT}\end{array}$ & 143 & $\begin{array}{l}\text { Sungai } \\
\text { Nimbai }\end{array}$ & $\begin{array}{l}\text { Semak } \\
\text { belukar }\end{array}$ & $\begin{array}{l}\text { Dekat dengan pemukiman dan } \\
\text { areal } \\
\text { perkebunan kelapa sawit }\end{array}$ \\
\hline $\begin{array}{l}00^{\circ} 52^{\prime} 4,2 ” \text { LS } \\
133^{\circ} 50^{\prime} 51,9 ” \text { BT }\end{array}$ & 114 & $\begin{array}{l}\text { Sungai } \\
\text { Nimbai }\end{array}$ & $\begin{array}{l}\text { Padang } \\
\text { rumput }\end{array}$ & $\begin{array}{l}\text { Jauh dari pemukiman dan } \\
\text { merupakan pertemuan di antara } \\
\text { Sungai Nimbai dan Sungai Prafi }\end{array}$ \\
\hline $\begin{array}{l}00^{\circ} 55^{\prime} 34,99^{\prime \prime} \mathrm{LS} \\
133^{\circ} 48^{\prime} 26,1^{\prime \prime} \mathrm{BT}\end{array}$ & 241 & $\begin{array}{l}\text { Sungai } \\
\text { Aimasi }\end{array}$ & $\begin{array}{l}\text { Sekunder } \\
\text { muda }\end{array}$ & $\begin{array}{l}\text { Tepat di bendungan Sungai } \\
\text { Aimasi yang jauh dari } \\
\text { pemukiman }\end{array}$ \\
\hline $\begin{array}{l}00^{\circ} 55^{\prime} 16,2^{\prime \prime} \mathrm{LS} \\
133^{\circ} 48^{\prime} 27,3 \text { " BT }\end{array}$ & 239 & $\begin{array}{l}\text { Sungai } \\
\text { Aimasi }\end{array}$ & Primer & $\begin{array}{l}\text { Tepat di bendungan Sungai } \\
\text { Aimasi yang jauh dari } \\
\text { pemukiman }\end{array}$ \\
\hline $\begin{array}{l}00^{\circ} 54^{\prime} 57,5^{\prime \prime} \mathrm{LS} \\
133^{\circ} 48^{\prime} 20,7^{\prime \prime} \mathrm{BT}\end{array}$ & 218 & $\begin{array}{l}\text { Sungai } \\
\text { Aimasi }\end{array}$ & $\begin{array}{l}\text { Sekunder } \\
\text { muda }\end{array}$ & $\begin{array}{l}\text { Tepat di bendungan Sungai } \\
\text { Aimasi yang jauh dari } \\
\text { pemukiman }\end{array}$ \\
\hline
\end{tabular}

\section{Variabel Pengamatan}

Variabel yang diamati dalam penelitian ini adalah variasi jenis habitat dan potensi vegetasi riparian pada seluruh tingkat pertumbuhan.

1. Potensi variasi jenis habitat vegetasi riparian ikan pelangi arfak

Variasi jenis vegetasi riparian ikan pelangi arfak didasarkan pada tipe tutupan dan kehadiran jenis vegetasi berdasar tinjauan awal lokasi dan studi pustaka. Berdasarkan studi pustaka variasi jenis habitat ikan pelangi arfak oleh Manangkalangi dkk. (2012), terdiri atas vegetasi riparian primer, riparian sekunder dan hutan terbuka.

2. Potensi jenis vegetasi

Potensi jenis vegetasi yang diamati meliputi:

a. Semai meliputi nama spesies, famili dan jumlah indvidu.

b. Pancang terdiri dari nama spesies, famili dan jumlah individu. 
c. Tiang meliputi nama jenis, diameter batang, tinggi bebas cabang dantinggi keseluruhan pohon.

d. Pohon meliputi nama jenis, diameter batang, tinggi bebas cabang dan tinggi keseluruhan pohon.

\section{Teknik Pengumpulan Data}

Data yang dikumpulkan terdiri dari data primer dan data sekunder. Pengambilan data primer dilakukan dengan melakukan pengamatan lapangan pada hutan riparian tingkat semai, pancang, tiang dan pohon di sungai Nimbai Distrik Prafi Manokwari. Pengumpulan data riparian tingkat semai dilakukan dengan cara membentuk petak ukur $2 \mathrm{~m} \times 2 \mathrm{~m}$ dalam petak induk pengamatan, kemudian mengidentifikasi jenis (genus dan spesies) dan menghitung jumlah individu, tingkat pancang dengan cara membentuk petak ukur $5 \mathrm{~m} \times 5 \mathrm{~m}$ pada petak induk pengamatan, selanjutnya mengidentifikasi jenis tumbuhan (genus dan spesies) dan menghitung jumlah individu, tingkat tiang dengan cara membentuk petak ukur $10 \mathrm{~m} \times 10 \mathrm{~m}$ kemudian mengindentifikasi jenis (genus dan spesies) dan mengukur diameter batang $(\mathrm{cm})$ juga tinggi batang bebas cabang $(\mathrm{m})$ dan tinggi batang keseluruhan $(\mathrm{m})$. Pada tingkat pohon dengan cara membentuk petak ukur $20 \mathrm{~m}$ $\times 20 \mathrm{~m}$ kemudian mengidentifikasi jenis (genus dan spesies), mengukur diameter batang $(\mathrm{cm})$, tinggi batang bebas cabang (m) dan tinggi batang keseluruhan (m). Secara umum teknik pengumpulan data disajikan pada tabel 2 .

Selain data primer, penelitian ini juga menggunakan data sekunder yang terkait dengan kondisi vegetasi riparian habitat ikan pelangi Arfak di sungai Nimbai dan Aimasi yang berasal dari penelitianpenelitian sebelumnya meliputi populasi dan reproduksi ikan pelangi arfak.

Tabel 2. Tingkatan pertumbuhan, ukuran petak ukur dan jenis data

\begin{tabular}{|c|c|c|c|}
\hline No. & $\begin{array}{c}\text { Tingkat } \\
\text { pertumbuhan }\end{array}$ & $\begin{array}{l}\text { Ukuran petak } \\
\text { ukur }(\mathrm{m})\end{array}$ & Jenis data \\
\hline 1. & Semai & $2 \times 2$ & Genus dan spesies \\
\hline 2. & Pancang & $5 \times 5$ & Genus dan spesies \\
\hline 3. & Tiang & $10 \times 10$ & $\begin{array}{l}\text { Genus, spesies, diamater, tinggi batang bebas cabang, } \\
\text { tinggi batang keseluruhan }\end{array}$ \\
\hline 4. & Pohon & $20 \times 20$ & $\begin{array}{l}\text { Genus, spesies, diamater, tinggi batang bebas cabang, } \\
\text { tinggi batang keseluruhan }\end{array}$ \\
\hline
\end{tabular}

Juga data kondisi sosial masyarakat sekitar sungai Nimbai dan Aimasi dan keadaan umum yang menggambarkan kondisi bentang alam lokasi penelitian.

\section{Pelaksanaan Penelitian}

Penelitian dilakukan di sepanjang sistem sungai Prafi yakni sungai Nimbai dan sungai Aimasi. Sungai Nimbai berada di sekitar areal perkebunan kelapa sawit (crude palm oil) dan pemukiman masyarakat sementara sungai Aimasi relatif jauh dari atau tidak bersentuhan langsung dengan aktivitas masyarakat. Penelitian dilaksanakan mengacu pada arah aliran sungai. Selanjutnya dilakukan penetapan transek pengamatan (lokasi) berdasarkan tipe tutupan hutan. Setelah itu penetapan dan pembuatan jalur pengamatan yang arahnya tegak lurus 
arah aliran sungai sepanjang $20 \mathrm{~m}-50 \mathrm{~m}$ (disesuaikan dengan kondisi tepian sungai [topografi, tutupan dan sebagainya]). Selanjutnya peletakkan dan pembuatan petak ukur (PU) disesuaikan dengan tingkatan pertumbuhan vegetasi (tabel 1). Sistem peletakkan PU menggunakan metode terpusat atau bersarang (nesting plot).

\section{Pengolahan Data}

Pengolahan data dalam penelitian ini dilakukan dengan cara melakukan analisis vegetasi untuk mendapatkan informasi kerapatan, frekuensi jenis, dominansi dan indeks nilai penting. Adapun gambaran mengenai struktur komunitas vegetasi riparian dilakukan dengan pendekatan analisis sebagai berikut:

a. Kepadatan $(\mathbf{K})$ dan Kepadatan

\section{Relatif (KR)}

Kepadatan jenis $(\mathrm{K})$

$=\frac{\text { Jumlah individu tiap jenis }}{\text { Luas petak contoh }\left(\mathrm{m}^{2}\right)}$

Kepadatan relatif (KR dalam \%) $=\frac{\text { Jumlah individu tiap jenis }}{\text { Jumlah individu seluruh jenis }}$

b. Frekuensi (F) dan Frekuensi

Relatif (FR)

Frekuensi jenis (Fi)

$=$ Jumlah petak ditemukannya jenis ke-i

Jumlah total petak

Frekuensi relatif $\left(\right.$ FR dalam \%) $\quad=\frac{\text { Frekuensi jenis ke-i }}{\text { Frekuensi seluruh jenis }}$

c. Dominasi (D) dan Dominasi

Relatif (DR)

Dominasi (D)

$=\frac{\text { Luas bidang dasar suatu jenis }}{\text { Luas petak contoh }}$

Dominasi Relatif (DR) (FR dalam

$\%)$

Dominasi suatu jenis

Dominasi total seluruh jenis

\section{d. Indeks Nilai Penting (INP)}

$\mathrm{INP}=\mathrm{FR}+\mathrm{KR}$ (vegetasi riparian tingkat semai dan pancang)

$\mathrm{NP}=\mathrm{FR}+\mathrm{KR}+\mathrm{DR}$ (vegetasi riparian tingkat tiang dan pohon)

\section{Analisis Data}

Data yang diperoleh dari hasil penelitian ini dianalisis secara deskriptif sesuai dengan tingkatan data. Analisa data disajikan dalam bentuk tabel dan peta termasuk gambar untuk menunjukkan tipe vegetasi riparian pada habitat ikan pelangi arfak di sungai Nimbai dan Aimasi.

\section{HASIL DAN PEMBAHASAN}

\section{Tipe Tutupan Vegetasi Riparian Di Sungai Nimbai dan Aimasi}

Vegetasi riparian adalah vegetasi yang tersebar dan tumbuh di sepanjang aliran sungai (tepi kiri dan kanan sungai), yang secara langsung maupun tidak langsung dipengaruhi oleh aliran sungai. Secara umum areal vegetasi riparian yang 
ditemukan pada sungai Nimbai rata-rata jaraknya berada antara $10 \mathrm{~m}-100 \mathrm{~m}$ dari badan sungai utama. Sungai Nimbai dan sungai Aimasi bersumber dari kawasan Pegunungan Arfak yang alirannya didominiasi oleh batuan lime stone dan beraliran jernih dengan tingkat $\mathrm{pH}$ berkisar antara 6,63-7,98.

Kedua sungai itu merupakan bagian dari sistem sungai Prafi yang secara administratif terletak di Distrik Prafi Kabupaten Manokwari. Distrik tersebut sebagian besar memiliki morfologi geografis cenderung datar dan bergelombang ringan, dengan luasan mencapai lebih dari 100.000 hektar, dan berada pada kisaran ketinggian antara $0 \mathrm{~m}$ $-100 \mathrm{~m}$ di atas permukaan laut (m dpl) seperti digambarkan Manangkalangi dkk. (2012).

Kawasan ini berada di bagian utara Kepala Burung Pulau Papua (Vogelkop) yang mengitari kawasan Pegunungan Arfak. Areal ini sejak awal tahun 1970-an merupakan kawasan hutan primer (virgin forest) yang kaya akan keanekaragaman hayati. Namun dengan adanya status kawasan ini sebagai hutan konversi, maka areal ini dimanfaatkan sebagai pemukiman dan industri perkebunan kelapa sawit. Pada sebagian kawasan ini, arealnya telah berkembang menjadi pemukiman penduduk yang berasal dari luar daerah Papua (transmigrasi), areal persawahan dan areal industri perkebunan sawit (oil palm estate). Aktivitas pemanfaatan lahan tersebut telah mengubah dan menghilangkan berbagai potensi hutan dan biota yang berada pada kawasan ini baik secara langsung maupun tidak langsung.

Secara umum terdapat perbedaan tipe tutupan vegetasi/hutan riparian pada areal sungai Nimbai dan Aimasi. Pada sungai
Nimbai terdiri atas 3 (tiga) tipe tutupan hutan yaitu hutan sekunder tua, semak belukar dan padang rumput dan sungai Aimasi terdiri atas 2 (dua) tipe tutupan yaitu primer dan sekunder muda. Masih bertahannya vegetasi riparian primer, sekunder tua dan sekunder muda pada sungai Nimbai dan sungai Aimasi, karena relatif masih terjaga, sementara yang bertipe semak belukar dan padang rumput karena telah mengalami perubahan peruntukkan dan berada persis di sekitar areal perkebunan kelapa sawit. Berbagai tipe tutupan yang terbentuk ini dipengaruhi beberapa faktor, terdiri dari faktor alam dan aktivitas manusia. Faktor alam seperti erosi, topografi dan curah hujan sementara faktor aktivitas manusia seperti pembukaan lahan untuk kebun palawija, tanaman jangka panjang dan aktivitas perusahaan lahan kelapa sawit.

\section{Komposisi Jenis Vegetasi Riparian Di Sungai Nimbai dan Aimasi}

Komposisi Jenis Vegetasi Riparian Hutan Sekunder Tua di Sungai Nimbai

Kondisi vagetasi di areal hutan sekunder tua di sungai Nimbai cukup dipengaruhi oleh keberadaan perladangan yang masih aktif, meski arealnya tidak begitu luas. Selain itu pada lokasi ini juga menjadi pilihan pengembalaan ternak warga sekitar. Walaupun begitu, secara umum jarak lokasi ini yang cukup jauh dari pemukiman masyarakat cukup membantu menekan kerusakannya. Pada areal ini ditemukan komposisi vegetasi berkayu seluruh tingkatan pertumbuhan sebanyak 25 famili yang terbagi dalam 47 genus dan 56 spesies. Moraceae merupakan famili paling dominan dengan jumlah total 8 spesies. Adapun pertumbuhan vegetasi tingkat semai pada 
areal ini tersusun atas 18 famili, 30 genus dan 36 spesies, tingkat pancang 20 famili terbagi dalam 30 genus dan 33 spesies, tingkat tiang 15 famili 16 genus dan 20 spesies dan tingkat pohon 16 famili 20 genus dan 21 spesies.

\section{Komposisi Jenis Vegetasi Riparian pada Hutan Primer di Sungai Aimasi}

Jauh dari pemukiman penduduk dan bertopografi cukup terjal yang sungainya beraliran deras, selain itu merupakan sumber air bagi lahan pertanian di dataran Prafi, menjadikan kesehatan hutan primer di sungai Nimbai cukup terpelihara dengan baik. Adapun komposisi tumbuhan berkayu pada areal ini untuk selurh tingkat pertumbuhan tergolong dalam 27 famili, 38 genus dan 46 spesies. Famili Moraceae merupakan yang paling dominan dengan jumlah total 7 jenis (spesies). Pada tingkat pertumbuhan semai terdapat 18 famili dengan 21 genus dan 23 spesies, berikut tingkat pancang 21 famili terbagi dalam 28 genus dan 32 spesies, tingkat tiang 19 famili 22 genus dan 24 spesies, tingkat pohon 11 famili 14 genus dan 15 spesies.

\section{Komposisi Jenis Vegetasi Riparian pada Hutan Sekunder Muda di Sungai Aimasi}

Komposisi tumbuhan berkayu pada hutan riparia sekunder muda di sungai Aimasi untuk seluruh tingkatan pertumbuhan tergolong dalam 15 famili, 20 genus dan 24 spesies. Famili yang paling dominan adalah Euphorbiaceae dengan jumlah total 7 spesies. Pada tingkat semai terdapat 7 famili yang terbagi dalam 9 genus dan 11 spesies, tingkat pancang 7 famili terbagi dalam 10 genus dan 12 spesies, tingkat tiang 7 famili terbagi dalam 8 genus dan 9 spesies, tingkat pohon terdapat 8 famili yang terbagi dalam 9 genus dan 11 spesies.

\section{Komposisi Jenis Vegetasi Riparian Semak Belukar di Sungai Nimbai}

Komposisi semak belukar di sungai Nimbai untuk seluruh tingkatan pertumbuhan tergolong dalam 9 famili, 12 genus dan 12 spesies. Famili yang paling dominan adalah Euphorbiaceae dengan jumlah total 3 spesies. Pada tingkat semai terdapat 6 famili yang terbagi dalam 6 genus dan 6 spesies, tingkat pancang 9 famili terbagi dalam 11 genus dan 11 spesies, tingkat tiang 3 famili terbagi dalam 3 genus dan 3 spesies, tingkat pohon terdapat 2 famili yang terbagi dalam 2 genus dan 2 spesies.

\section{Struktur Vegetasi Riparian Hutan Sekunder Tua di Sungai Nimbai}

\section{Tumbuhan Bawah}

Tumbuhan bawah yang dimaksudkan merupakan jenis vegetasi non kayu yang tumbuh terutama di bawah tegakan utama atau areal terbuka lainnya. Keragaman jenis tumbuhan bawah yang ditemukan pada areal ini terdiri atas 39 jenis spesies yang didominasi famili Asteraceae. Mycania micrantha merupakan jenis penting dalam penyusun struktur vegetasi pada tingkatan pertumbuhan ini, disusul jenis-jenis lainnya seperti Bidens pilosa, Saccarum sp., Pueraria javanica dan Celosia argentea. Terlihat bahwa jenis Micania micrantha sangat mendominasi areal ini dengan nilai INP-nya yang tinggi (15\% dari total nilai INP pada tingkatan ini). Hal ini menunjukkan bahwa jenis Micania micrantha mampu beradaptasi dengan baik pada areal ini, baik pada kepadatan populasi maupun sebaran atau distribusi individunya (12,048\%). Pada 
jenis berikutnya bila dilihat dari kepadatan populasi, Saccarum sp. lebih tinggi dibanding jenis Bidens pilosa, namun bila dilihat dari penyebaran jenis, Bidens pilosa lebih baik dibanding Saccarum sp. $\quad(7,229 \%$ dibanding $3,614 \%$ ). Hal ini dimungkinkan karena benih Bidens pilosa lebih mudah terdistribusi karena memiliki morfologi biji yang memudahkan dalam perpindahan (mudah menempel pada obyek tertentu) melalui ternak atau hewan liar, dan manusia yang melewatinya atau mudah terbawa air dan angin.

\section{Tingkat Semai}

Permudaan semai biasanya terdapat dibawah tegakkan utama atau pada tegakkan lain yang bisa menjadi tempat berlindung, dan sering merupakan anakan dari vegetasi utama dengan tinggi kurang dari $150 \mathrm{~cm}$. Pada areal ini, tegakkan semai ditemukan sangat variatif atau sebanyak 35 spesies dengan famili dominan yakni Moraceae dan Rubiaceae. Piper aduncum adalah merupakan jenis penting penyusun populasi tingkatan ini disusul jenis-jenis lain seperti Macaranga mappa, Ficus robusta, Ficus sp. dan Premna corymbosa. terlihat bahwa Piper anduncum sangat mendominasi areal ini dengan INP 36,957\%. Tingkat kepadatan individu per satuan hektarnya juga sangat tinggi. Untuk tingkat distribusi pun lebih tinggi dibanding jenis Macaranga Mappa dan Ficus Robusta yang masing-masing hanya 8,696\%. Macaranga mappa dan Ficus robusta sendiri memiliki INP tak berbeda yakni 17,391\% dan 16,667\%.

\section{Tingkat Pancang}

Tumbuhan tingkat pancang adalah anakan pohon dengan tinggi lebih dari $150 \mathrm{~cm}$ dan diameter batang kurang dari $10 \mathrm{~cm}$. Pada areal hutan sekunder tua di sungai Nimbai ini, keragamaan permudaan tingkat pancang dijumpai sebanyak 33 jenis. Adapun famili dominan di areal ini adalah Euphorbiaceae dan Moraceae. Piper aduncum merupakan yang paling tinggi nilai INP-nya disusul dibanding jenisjenis lain seperti Melastoma malabatricum, Macaranga mappa, Premna corymbosa dan Gliricidia sepium. terlihat perbedaan mencolok antara Piper aduncum (INP- 50,498\%) dengan empat jenis tumbuhan lainnya pada daftar nomor satu sampai lima, yang hanya berada pada kisaran INP 13,285\% persen sampai $15,941 \%$. Tingkat kerapatan, sebaran dan penguasaan areal tumbuh Piper anduncum juga sangat tinggi.

\section{Tingkat Tiang}

Vegetasi tingkat tiang biasanya merupakan tumbuhan anakan yang hampir dewasa yang telah masuk dalam kelas pohon, dengan ukuran diameter antara $10 \mathrm{~cm}$ dan $20 \mathrm{~cm}$. Pada areal ini, keberadaan vegetasi tingkat tiang ditemukan sebanyak 20 jenis dengan famili dominan Moraceae. Piper aduncum adalah jenis yang cukup dominan menyusul jenis-jenis lainnya secara berurutan yakni Macaranga mappa, Ficus sp., Artocarpus altilis dan Homalium foetidum. keberadaan Piper aduncum menempati posisi paling dominan dibanding jenis lainnya (INP63,021). Vetegasi ini juga memiliki tingkat kepadatan $(23,333 \%)$ dan distribusi $(18,182)$ yang paling tinggi. Sementara itu jenis Ficus sp. dan Artocarpus altilis memiliki nilai INP yang hampar sama, masing-masing $32,758 \%$ dan $30,543 \%$. Tingkat dominasi antara kedua jenis ini terlihat tipis, hanya $11,395 \%$ dan $11,452 \%$. 


\section{Tingkat Pohon}

Vegetasi tingkat pohon didefinisikan sebagai tumbuhan berkayu yang memiliki diameter lebih dari $20 \mathrm{~cm}$. Vegetasi tingkat ini adalah vegetasi puncak yang telah memiliki perawakan sempurna sesuai jenisnya. Pada tipe hutan sekunder tua di sungai Nimbai, keragaman vegetasi tingkat pohon ditemukan sebanyak 21 jenis dengan famili dominan Moraceae. Artocarpus altilis merupakan vegetasi penting penyusun populasi di areal ini. Selain itu terdapat vegetasi lainnya yakni Ficus sp., Macaranga mappa, Dysoxylum mollissimum dan Ficus robusta. terlihat bahwa Artocarpus altilis memiliki posisi puncak sebagai jenis yang paling tinggi keberadaannya dengan (INP- 63,920\%) di areal hutan sekunder tua sungai Nimbai. Jenis ini juga bahkan memiliki tingkat kepadatan, distribusi dan dominasi yang lebih tinggi dibanding jenis lainnya. Artocarpus altilis (DR-16,630) terlihat hanya memiliki perbedaan dominasi yang tidak terlalu jauh dengan jenis Ficus sp. $(14,882 \%)$. Selain itu pada jenis Dysoxylum mollissimum yang memiliki INP lebih tinggi $(18,726 \%)$ dibanding Ficus robusta (18,168\%), namun tingkat sebaran Ficus robusta (7,317\%) lebih baik disbanding Dysoxylum mollissimum yang hanya $(4,878 \%)$.

\section{Struktur Vegetasi Berkayu pada Hutan Primer di Sungai Aimasi}

\section{Tumbuhan Bawah}

Hutan primer sungai Aimasi cukup memiliki keragaman jenis tumbuhan bawah yang tinggi yakni sebanyak 15 spesies yang didominasi famili Poaceae. Widelia biflora merupakan jenis penting pada areal ini disusul jenis-jenis lain seperti Eragrostis spectabilis, Imperata cylindrica, Mikania micrantha dan
Eleocaris indica. terlihat bahwa keberadaan Widelia biflora merupakan jenis yang paling dominan (INP$25,645 \%$ ) dengan kepadatan populasi 20.000 jenis per satuan hektar. Meski begitu, sebaran jenis ini tidak lebih baik dari Mikania micrantha yang hanya memiliki INP-19,823\%. Sebaran Widelia biflora hanya menempati 4,348 persen dari keseluruhan areal, sementara Mikania micrantha menempati $6,521 \%$ areal.

\section{Tingkat Semai}

Keragaman jenis tingkat semai yang ditemukan pada areal hutan primer di sungai Aimasi cukup tinggi dengan jumlah 23 jenis (spesies) dengan famili paling dominan yakni Burseraceae dan Moraceae. Pometia pinnata merupakan jenis penting penyusun populasi pada tingkat ini disusul jenis-jenis lainnya yakni Dendrocnide macrostigma, Duabanga moluccana, Euodia bounvickii dan Macaranga mappa. keberadaan Pometia pinnata sangat tinggi dengan INP-26,580\%. Jenis ini juga memiliki kepadatan, tingkat distribusi dan dominasi yang terpaut cukup jauh dari jenis lain. Pada jenis seperti Dendrocnide macrostigma dan Duabanga moluccana, hanya memiliki tingkat sebaran yang berbeda, masing-masing $7,407 \%$ dan $3,704 \%$ meski tingkat kepadatan per hektar sama yakni 1500 individu. Untuk jenis Euodia bounvickii dan Macaranga mappa memiliki INP yang sama yakni 9,586\%.

\section{Tingkat Pancang}

Keragaman struktur vegetasi yang terbentuk di areal ini sebanyak 32 jenis, didominasi oleh jenis yang berasal dari famili Moraceae dan Myristicaceae. Pometia pinnata adalah jenis yang paling 
dominan berikut Teijsmaniodendron bogoriense, Ficus robusta, Terminalia canaliculate dan Garcinia lattisima. tergambarkan bahwa Pometia pinnata mendominasi struktur vegetasi tingkat pancang di hutan primer sungai Aimasi, dengan nilai INP-19,176\%. Meski begitu, tingkat kepadatan jenis ini sama banyak dengan Teijsmaniodendron bogoriense dan Ficus robusta, sejumlah masingmasing 40 individu per satuan hektar.

\section{Tingkat Tiang}

Pada struktur tingkat tiang di kawasan ini, populasi didominasi oleh famili Moraceae. Adapun jumlah spesies sebanyak 24 jenis dengan yang paling dominan adalah Pometia pinnata, berikut Macaranga mappa, Canarium hirsutum, Premna corymbosa dan shillinglawii. terlihat bahwa Pometia pinnata merupakan jenis paling dominan dibandingkan jenis lain pada vegetasi tingkat tiang di kawasan ini, dengan kepadatan populasi yang sangat tinggi $(\mathrm{KR}=17,647 \%)$, berikut penguasaan areal yang sangat luas $\mathrm{DR}=20,847 \%$ ), dan penyebaran yang cukup tinggi (FR=12,903\%). Selain itu Canarium hirsutum dan Premna corymbosa memiliki tingkat dominasi yang hamper sama $\quad(\mathrm{INP}=17,600 \%) \quad$ dan (INP $=17,103 \%$ ). Canarium hirsutum sedikit lebih tinggi ( $\mathrm{DR}=5,266 \%)$ karena tingkat penguasaan arealnya yang sedikit lebih baik dibanding Premna corymbosa $(\mathrm{DR}=4,769 \%)$.

\section{Tingkat Pohon}

Jenis-jenis vegetasi berkayu hutan primer pada tingkat pohon di kawasan sungai Aimasi, berasal dari sejumlah famili seperti Burseraceae, Euphorbiaceae, Moraceae dan Myristicaceae. Adapun jumlah jenisnya sebanyak 15 jenis dengan Pometia pinnata sebagai jenis paling dominan Pometia pinnata, diikuti jenis Artocarpus altilis, Teijsmaniodendron bogoriense, Homalium foetidum dan Sterculia shillinglawii. Terlihat bahwa Pometia pinnata sangat mendominasi vegetasi tingkat pohon pada kawasan hutan primer sungai Aimasi ( $\mathrm{INP}=69,923 \%)$, dengan pengguasaan areal yang sangat luas $(\mathrm{DR}=$ 26,391\%) bahkan kerapatan yang sangat tinggi $(\mathrm{KR}=27,907 \%)$, dibanding spesies yang lain di kawasan tersebut. Meski begitu, pada sebaran vegetasi, Pometia pinnata yang dominasinya (INP $=47,015 \%$ ) berada satu tingkat di bawah Artocarpus altilis, sama-cukup merata atau sama, masing-masing mencapai $(\mathrm{FR}=15,625 \%)$.

\section{Struktur Vegetasi Berkayu pada Hutan Sekunder Muda di Sungai Aimasi}

Tumbuhan Bawah

Tumbuhan bawah pada hutan sekunder muda di sungai Aimasi sebanyak 26 jenis yang didominasi famili Poaceae. Bidens pilosa merupakan jenis penting dalam penyusun populasi pada tingkat ini disusul jenis-jenis lain seperti Mikania micrantha, Saccarum sp., Donax coniformis dan Celosia argentea. Bidens pilosa didapati muncul sebagai jenis sangat dominan $(24,543 \%$ dari total nilai INP pada tingkatan ini). Tingkat kerapatannya juga cukup tinggi $(\mathrm{KR}=$ $33,702 \%$ ) disbanding spesies lain pada kawasan ini. Meski begitu penyebarannya tidak terlalu luas $(\mathrm{FR}=15,385 \%)$ dibanding Mikania micrantha yang penyebarannya $(10,769 \%)$ meski hanya mendominasi kawasan ini sebesar (INP = $20,161 \%)$. 


\section{Tingkat Semai}

Tingkat permudaan semai pada kawasan ini didominasi famili Euphorbiaceae dan Moraceae dengan jumlah total spesies yang ditemukan 11 jenis. Piper aduncum merupakan jenis penting penyusun populasi pada tingkat ini disusul jenis lainnya seperti Ficus sp., Mallotus rhizonoides, Macaranga mappa dan Duabanga moluccana. terlihat bahwa jenis Piper aduncum sangat mendominasi kawasan ini bahkan hampir setengah dari nilai total INP pada tingkatan ini atau $46,5805 \%$. Tingkat kerapatan individu per satuan hektarnya juga sangat tinggi $(\mathrm{K}=4000)$ termasuk penguasaan areal yang mencapai $(\mathrm{FR}=45,161 \%)$. Selain itu sesuai yang terlihat pada tabel ini, Duabanga moluccana yang INP-nya lebih rendah $(11,226 \%)$ dibanding Macaranga mappa $(12,452 \%)$ tingkat kerapatannya lebih tinggi $(8,000 \%)$ dibanding Macaranga mappa (6,000\%).

\section{Tingkat Pancang}

Struktur vegetasi pada tingkat pancang terdiri atas jenis-jenis tumbuhan pionir seperti Piper aduncum, Macaranga mappa dan Ficus septica. Selain itu terdapat jenis lain seperti Duabanga moluccana dan Mallotus rhizonoides. terlihat bahwa secara umum jenis-jenis yang mendominasi tingkat pancang pada areal ini berbeda dengan jenis-jenis yang mendominasi hutan primer, dimana pada areal hutan primer, jenis Pometia pinata, tumbuhan yang buahnya bisa dikonsumsi manusia sekaligus kayunya bisa dimanfaatkan untuk kebutuhan bangunan, karena termasuk kayu keras, lebih dominan, sementara pada areal ini yang sangat dominan adalah Piper aduncum. Adapun pada areal ini keberadaan Piper anduncum selain paling dominan (INP $=67,463 \%)$, tingkat kepadatannya juga sangat tinggi $\quad(\mathrm{KR}=41,463 \%)$ dibanding jenis lain.

\section{Tingkat Tiang}

Vegetasi riparia tingkat tiang pada tipe hutan sekunder muda di sungai Aimasi terdiri atas 9 jenis. Jenis yang dominan adalah Falcataria moluccana, Ficus sp., Duabanga moluccana, Cananga odorata dan Macaranga mappa. terlihat bahwa Falcataria moluccana $(\mathrm{INP}=64,355 \%)$ dan Ficus sp. $(\mathrm{INP}=63,141 \%)$ hampir sama-sama memiliki peran yang penting vegetasi tingkat tiang di areal ini menyusul Duabanga moluccana (INP= 52,312\%). Meski begitu kerapatan relatif (KR) Falcataria moluccana lebih rendah (18,182\%) dibanding Ficus sp. dan Duabanga moluccana yang sama-sama memiliki KR 22,727\%.

\section{Tingkat Pohon}

Vegetasi riparia tingkat pohon pada tipe hutan sekunder muda di sungai Aimasi terdiri atas 11 jenis dengan familifamili yang paling dominan adalah Euphorbiaceae, Fabaceae dan Moraceae. Adapun jenis-jenis yang dominan adalah Macaranga mappa, Falcataria moluccana, Duabanga moluccana diikuti jenis Homalium foetidum dan Rhus lamprocarpa. Macaranga mappa terlihat sebagai jenis yang paling dominan dengan $\quad \mathrm{INP}=63,791 \%$. Keberadaan Macaranga mappa yang merupakan tumbuhan perdu pada areal ini, yang telah mencapai pertumbuhan tingkat pohon, juga menjadi indikator bahwa areal ini tergolong sebagai hutan sekunder. Pada areal ini juga terlihat bahwa Falcataria mollucana yang meskipun lebih dominan (INP $=62,846 \%)$ dibanding Duabanga moluccana $(\mathrm{INP}=53,599 \%)$, namun kepadatan populasinya lebih rendah $(\mathrm{KR}=16,000 \%)$ dibanding kepadatan 
populasi Duabanga moluccana $(\mathrm{KR}=20,000 \%)$.

\section{Struktur Vegetasi Berkayu pada Semak Belukar di Sungai Nimbai}

\section{Tumbuhan Bawah}

Tumbuhan bawah pada tipe hutan semak belukar di sungai Nimbai tercatat sebanyak 20 jenis (spesies), yang didominasi oleh famili Poaceae sebanyak 7 jenis. Mimosa pudica merupakan jenis penting penyusun tumbuhan bawah di populasi ini disusul jenis-jenis seperti Hyptis capitata, Crotolaria indica, Widelia biflora dan jamaicensis. Mimosa pudica merupakan jenis paling dominan $(\mathrm{INP}=33,392 \%) \quad$ dengan tingkat kerapatan (KR) dan penyebaran (FR) yang juga tinggi $(21,488 \%)$ dan $(11,905 \%)$.

\section{Tingkat Semai}

Pada tingkat permudaan semai, terdapat 6 jenis (spesies). Gliricidia sepium merupakan jenis penting dalam penyusun populasi di kawasan ini berikut jenis-jenis seperti Theobroma cacao, Piper aduncum, Macaranga mappa dan Pometia pinnata. Secara umum tergambarkan bahwa perbedaan yang tidak begitu jauh pada tiga jenis vegetasi dominan pada populasi tingkat semai di areal ini Gliricidia sepium (INP= $59,259 \%)$, Theobroma cacao $(52,593 \%)$ dan Piper aduncum (42,222\%). Tingkat kepadatan dan sebaran ketiga jenis ini juga tidak memiliki perbedaan yang mencolok. Di lapangan ditemukan bahwa lokasi ini terlihat keberadaan kebun coklat (Theobroma cacao) dalam kelompok kecil.

\section{Tingkat Pancang}

Pada tingkat pancang dijumpai 11 jenis permudaan dengan lima jenis dominan yaitu Theobroma cacao,
Gliricidia sepium, Mallotus rhizonoides, Piper aduncum dan Abroma augusta. Adapun famili yang menyusun struktur vetegasi pada tingkat pancang pada areal ini didominasi oleh Euphorbiaceae. terlihat bahwa Theobroma cacao pada tingkat pancang merupakan jenis yang paling dominan dengan INP $=64,024 \%$. Meski begitu tingkat sebarannya terlihat sama dengan Gliricidia sepium, jenis dominan kedua $(\mathrm{INP}=56,707 \%)$ pada areal ini.

\section{Tingkat Tiang}

Vegetasi riparia tingkat tiang pada tipe hutan semak belukar di sungai Nimbai terdiri atas 3 jenis yaitu Theobroma cacao, Gliricidia sepium dan Alstonia scholaris. terlihat bahwa jenis Theobroma cacao dan Gliricidia sepium menguasai $94,198 \%$ dari total nilai INP pada tingkatan ini.

\section{Tingkat Pohon}

Vegetasi riparia tingkat pohon pada areal semak belukar di sungai Nimbai terdiri atas 2 jenis yaitu Mallotus rhizonoides dan Pometia pinnata. Keberadaan jenis Mallotus rhizonoides dan Pometia pinnata. Terindikasi pada areal ini hampir memiliki dominasi yang sama. Hanya tingkat sebaran kedua jenis yang berbeda, Mallotus rhizonoides $(\mathrm{DR}=$ $52,127 \%$ ) sementara Pometia pinnata $(\mathrm{DR}=47,873 \%)$.

\section{Struktur dan Komposisi Jenis Vegetasi Riparian Tumbuhan Bawah di Sungai Nimbai}

Pada habitat ikan pelangi arfak di sungai Nimbai ditemukan tipe tutupan lahan yang hanya terdapat tumbuhan bawah, terdiri atas 16 famili, 30 genus dan 31 spesies. Adapun famili paling dominan adalah Poacea (rumputrumputan) dengan jumlah 9 jenis. 
Tumbuhan bawah yang paling dominan adalah Echhornia crassipes, Ludwigia oktovalvis, Mimosa pudica, Solanum torfum dan Paspalum conjugatum. keberadaan jenis Echhornia crassipes cukup dominan $(\mathrm{INP}=37,196 \%)$, bahkan kerapatannya $(\mathrm{KR}=24,696 \%)$ juga lebih baik dibanding jenis lain. Meski begitu, tingkat sebarannya masih lebih baik Ludwigia oktovalvis yang memiliki nilai $\mathrm{INP}=31,564 \%$ atau berada satu tingkat dibawah jenis Echhornia crassipes. Adapun tingkat sebaran Echhornia crassipes adalah $\quad(\mathrm{FR}=12,500 \%)$ sementara Ludwigia oktovalvis $(13,750 \%)$.

\section{Kondisi Vegetasi Riparian dan Keberadaan Ikan Pelangi}

Berdasarkan hasil kajian oleh Manangkalangi dkk. (2014), ikan pelangi arfak di sungai Nimbai hanya ditemukan pada habitat yang kondisi vegetasinya masih terawat baik, berada pada bagian tengah ke arah hulu. Adapun tutupan vegetasi hutan riparian pada bagian tengah ke arah hulu di sungai Nimbai dipengaruhi oleh tutupan hutan sekunder tua. Sementara pada bagian tengah ke arah hilir, Manangkalangi dkk. (2014), tidak menemukan keberadaan ikan pelangi arfak, yang dalam penelitian ini diidentifikasi sebagai semak belukar dan padang rumput. Pada sungai Aimasi ikan pelangi arfak juga ditemukan, yang kondisi hutan ripariannya masih alami, bertipe hutan riparian yang dipengaruhi oleh hutan primer dan sekunder muda. Keberadaan ikan pelangi arfak di sungai Nimbai dan sungai Aimasi menurut Manangkalangi dkk. (2014) dan tipe vegetasi dalam penelitian ini dapat dilihat pada tabel 3 .

Tabel 3. Frekuensi kehadiran ikan pelangi arfak (Manangkalangi dkk. 2014) dan tipe vegetasi riparian di sungai Nimbai dan Aimasi

\begin{tabular}{|c|c|c|c|c|c|c|c|c|}
\hline \multirow{3}{*}{$\begin{array}{l}\text { Frek. } \\
\text { Kehadiran } \\
\text { ikan } \\
\text { pelangi }\end{array}$} & \multicolumn{8}{|c|}{ Tipe tutupan vevetasi riparian } \\
\hline & \multicolumn{4}{|c|}{ Sungai Aimasi } & \multicolumn{4}{|c|}{ Sungai Nimbai } \\
\hline & $\begin{array}{l}\text { Sekunder } \\
\text { tua }\end{array}$ & $\begin{array}{l}\text { Sekunder } \\
\text { tua }\end{array}$ & $\begin{array}{l}\text { Padang } \\
\text { rumput }\end{array}$ & $\begin{array}{l}\text { Semak } \\
\text { belukar }\end{array}$ & $\begin{array}{l}\text { Padang } \\
\text { rumput }\end{array}$ & $\begin{array}{l}\text { Sekunder } \\
\text { muda }\end{array}$ & Primer & $\begin{array}{l}\text { Sekunder } \\
\text { muda }\end{array}$ \\
\hline Titik1* & Ditemukan & & & & & & & \\
\hline Titik2* & & Ditemukan & & & & & & \\
\hline Titik3* & & & $\begin{array}{l}\text { Tidak } \\
\text { ditemukan }\end{array}$ & & & & & \\
\hline Titik4* & & & & $\begin{array}{l}\text { Tidak } \\
\text { ditemukan }\end{array}$ & & & & \\
\hline Titik5* & & & & & $\begin{array}{l}\text { Tidak } \\
\text { ditemukan }\end{array}$ & & & \\
\hline Titik6* & & & & & & Ditemukan & & \\
\hline Titik7* & & & & & & & Ditemukan & \\
\hline Titik8* & & & & & & & & Ditemukan \\
\hline
\end{tabular}

Keterangan (*): Titik 1 sampai titik 8 pada tabel ini mengacu pada tabel 1.

Keberadaan vegetasi riparian sangat berkaitan erat dengan kondisi ekosistem sungai. Vegetasi riparian berfungsi sebagai penyanggah suhu air sungai, menahan erosi bagian tepi sungai, menyanggah masukan partikel tersuspensi dan bahan pencemar dari daratan ke kolom air sungai, menyanggah kondisi 
hidrologi sungai dan sebagai habitat ikan dan menyediakan sumber makanan bagi hewan kecil yang merupakan makanan ikan termasuk ikan pelangi arfak.

Manangkalangi dkk. menemukan bahwa suhu air pada setiap titik di sungai Nimbai berbeda. Menurutnya, selain dipengaruhi ketinggian, juga diduga disebabkan kondisi naungan vegetasi riparian yang berbeda. Pada kondisi hutan riparian sekunder (titik 1 dan 2), keberadaan tajuk vegetasi membantu menahan kondisi suhu sungai tetap stabil sehingga cocok untuk ikan berkembangbiak, termasuk ikan pelangi arfak. Namun pada areal yang telah berubah menjadi semak belukar atau pada rumput (titik 3, 4 dan 5), tak sesuai lagi dalam menunjang kehidupan ikan pelangi arfak.

Untuk kondisi oksigen terlarut, seperti ditemukan Manangkalangi dkk. (2012), pada vegetasi riparian sekunder (titik 1 dan 2) lebih tinggi dan sesuai bagi ikan pelangi arfak, namun pada semak belukar atau pada rumput (titik 3, 4 dan 5) lebih rendah, yang tak sesuai bagi kehidupan ikan pelangi arfak. Pada struktur vegetasi, yang berfungsi menahan erosi ke bagian tepi sungai, berfungsi membuat kondisi air sungai relatif jernih sehingga ikut membantu ketersediaan makanan bagi ikan pelangi arfak, Manangkalangi dkk. (2012), menemukan makanan ikan pelangi arfak (makro-avertebrata) antara kondisi tutupan yang masih bervegetasi (sekunder muda) dan sudah kurang vegetasi atau tak bervegetasi (semak belukar dan padang rumput) berbeda. Pada kondisi hutan yang masih bervegetasi, kepadatan total dan keragaman makro-avertebrata lebih tinggi dibanding yang tak bervegetasi.
Tingkat kekeruhan air juga mempengaruhi habitat ikan pelangi arfak, karena struktur vegetasinya bisa menahan masukan partikel tersuspensi dan bahan pencemar air dari daratan ke kolom air sungai. Kondisi air yang relatif alami tanpa bahan pencemar (titik 1 dan 2) membantu ikan pelangi arfak relatif lebih baik dalam mencari makan. Menurut Manangkalangi (2019), tingkat kekeruhan air yang tinggi membuat pemangsaan semakin menurun.

Selain itu, struktur vegetasi riparian yang terendam dalam kolom air di bagian tepi sungai di sungai Nimbai (titik 1 dan 2) dan sungai Aimasi (titik 6, 7 dan 8), seperti dikemukakan Manangkalangi dkk. (2009), merupakan habitat yang terlindungi, dan merupakan tempat ikan pelangi arfak bereproduksi, seperti menempelkan telur dan tempat pembesaran larva.

Keberadaan serasah dari vegetasi riparian (titik 1 dan 2) berdasarkan penelitian Manangkalangi dkk. (2009), juga merupakan sumber makanan dalam ekosistem sungai bagi macro-avertebrata air, yang menjamin keanekaragaman dan kelimpahan makanan ikan, termasuk untuk ikan pelangi arfak. Pada kedua titik tersebut keberadaan macro-avertebrata masih cukup baik, namun berbeda pada daerah titik 4 dan 5. Di kedua lokasi tersebut, Leatemia dkk. (2017) mendapati, kepadatan macro-avertebrata yang rendah. Ini berkaitan dengan vegetasi riparian terbuka yang terdiri atas areal padang rumput, bekas kebun tradisional, lahan kelapa sawit, dan tempat penggembalaan ternak di tepi aliran sungai pada kedua titik. Degradasi vegetasi riparian menurut Agustina dan Arisoesilaningsih (2013), dapat 
menyebabkan fungsi riparian sebagai sumber nutrisi menjadi berkurang.

\section{DAFTAR PUSTAKA}

Agustina L dan Arisoesilaningsih E. 2013. Variasi profil vegetasi pohon riparian di sekitar mata air dan saluran irigasi tersier di Kabupaten Malang. Jurnal Biotropika, Vol 1 (3):85-89.

IUCN. 2012. The IUCN red list of threated species. https://www.iucnredlist.org/.

Leatemia SPO, Manangkalangi E, Lefaan PT, Peday HFZ dan Sembel L. 2017. Makroavertebrata bentos sebagai bioindikator kualitas air sungai Nimbai Manokwari, Papua Barat. Jurnal Ilmu Pertanian Indonesia (JIPI), Vol. 22 (1): 25-33.

Lekitoo K, Peday HFZ, Panambe N and Cabuy RL. 2017. Ecological and ethnobotanical facet of 'Kelapa Hutan' (Pandanus spp.) and perspectives towards its existence and benefit. International Journal of Botany, 13: 103-114.

Manangkalangi E, SPO Leatemia, PT Lefaan dan HFZ Peday. 2012. Strategi konservasi in situ ikan pelangi arfak (Melanotaenia arfakensis) pada sistem sungai Prafi Manokwari dan upaya domestikasinya. (Tidak diterbitkan).
Manangkalangi E, Rahardjo MF, Sjafii DS dan Sulistiono. 2009. Pengaruh kondisi hidrologi terhadap komunitas makroavertebrata di sungai Aimasi dan sungai Nimbai, Manokwari. Jurnal Perikanan dan Kelautan, Vol 5 (2): 99110.

Manangkalangi E, Leatemia SPO, Lefaan PT, Peday HFZ dan Sembel L. 2014. Kondisi habitat ikan pelangi arfak, Melanotaenia arfakensis Allen, 1990 di sungai Nimbai, Prafi Manokwari. Jurnal Iktiologi Indonesia, Vol 14 (1): 21-36.

Manangkalangi E, MF Rahardjo, Sjafei DS dan Sulistiono. 2009. Musim pemijahan ikan pelangi arfak (Melanotaenia arfakensis Allen) di sungai Nimbai dan Sungai Aimasi, Manokwari. Jurnal Iktiologi Indonesia, Vol 9 (1): 1-12.

Manangkalangi E, Rahardjo MF, Hadiaty RK, Hariyadi S dan Simanjuntak CPH. 2019. Tropic ecology of fish community at Nimbai Stream: Competition and predation interaction to arfak rainbowfish, Melanotaenia arfakensis, Allen, 1990. Jurnal Iktiologi Indonesia, Vol 19 (3): 449462. 


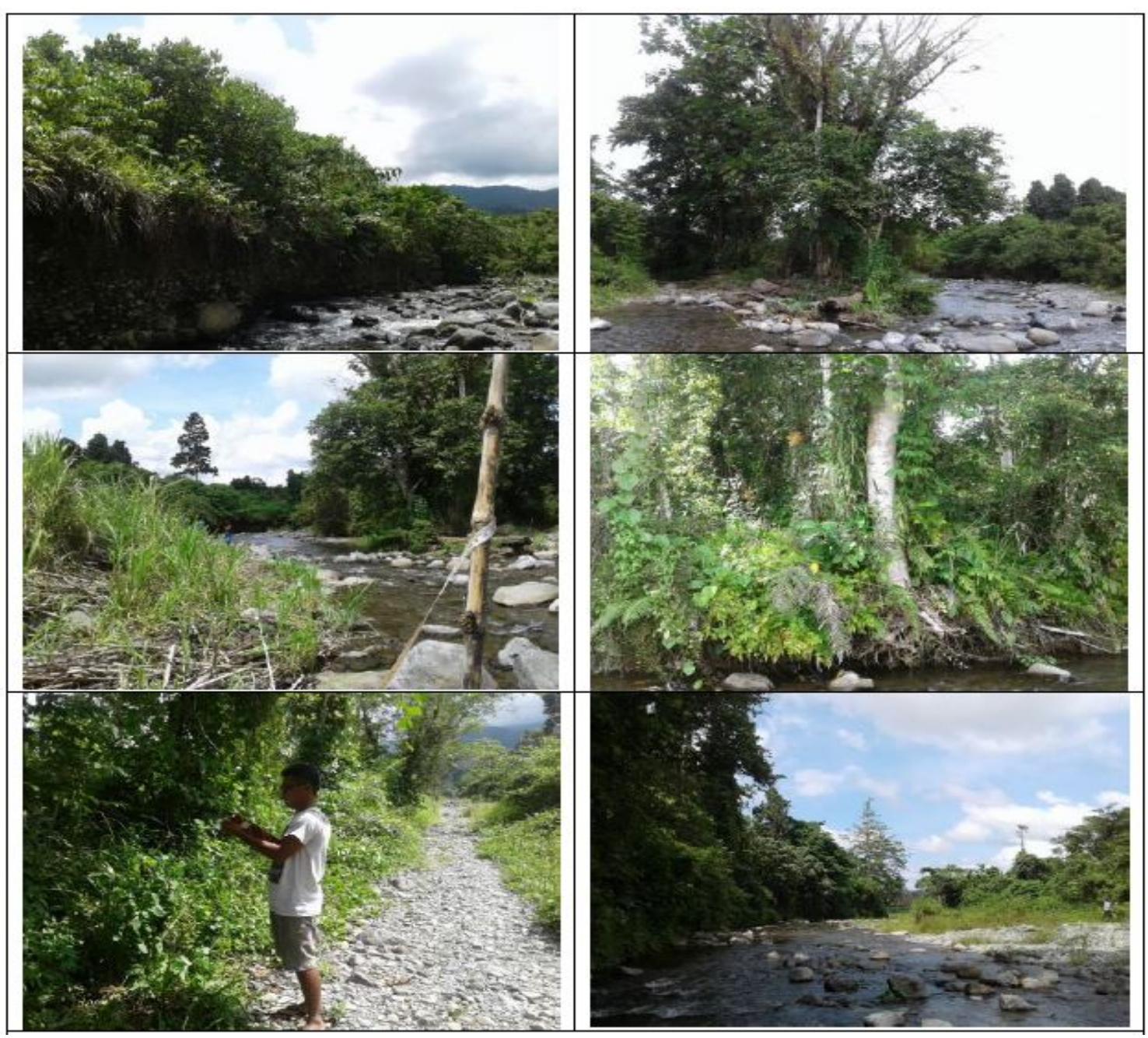

Gambar 1. Tipe vegetasi riparian pada sisi sungai Nimbai 


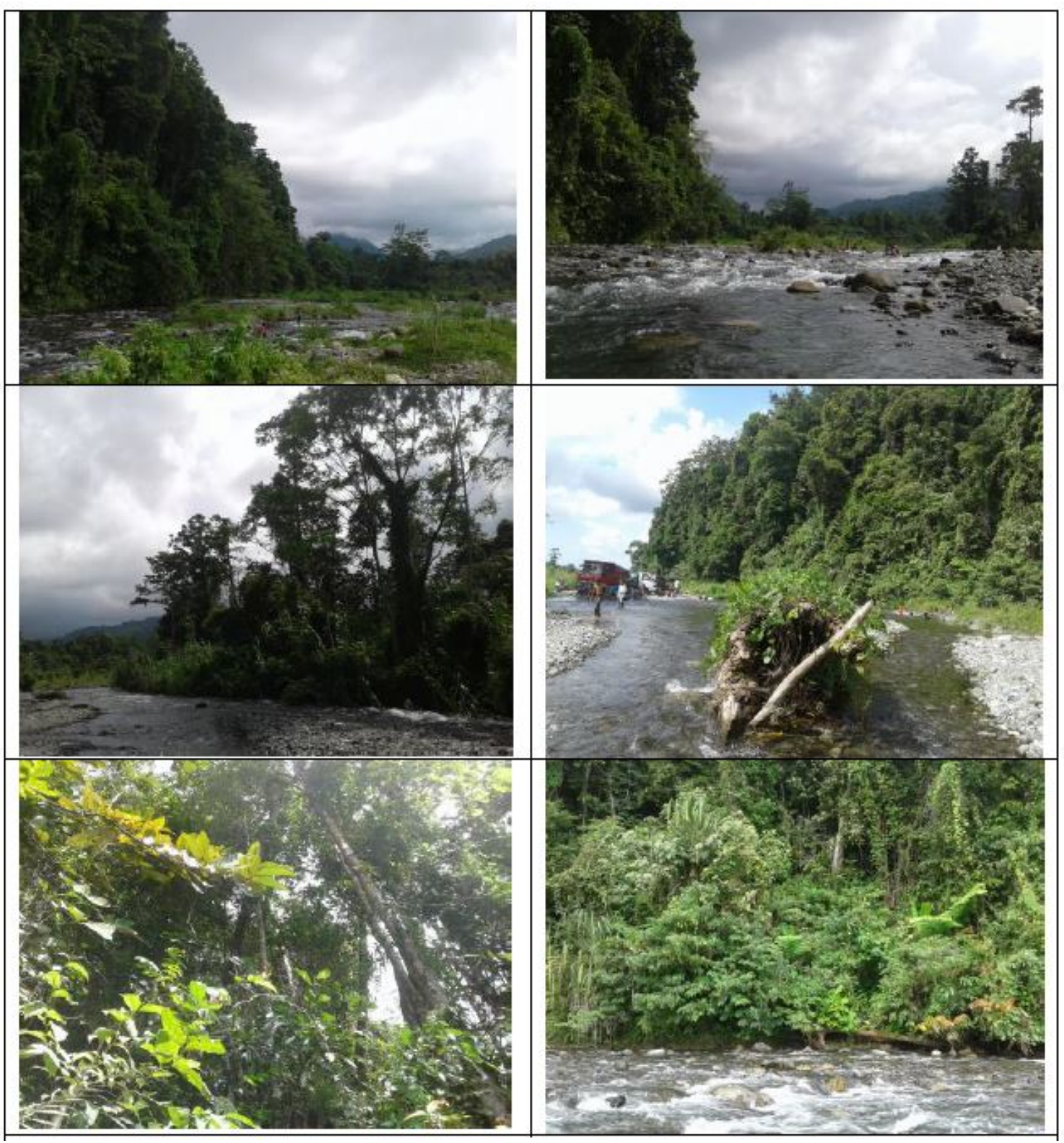

Gambar 2. Tipe vegetasi riparian pada sisi sungai Aimasi 